University of Nebraska - Lincoln

DigitalCommons@University of Nebraska - Lincoln

USDA National Wildlife Research Center - Staff Publications
U.S. Department of Agriculture: Animal and Plant Health Inspection Service

July 2002

\title{
Sustained evaluation of the effectiveness of detector dogs for locating brown tree snakes in cargo outbound from Guam
}

Richard M. Engeman

USDA-APHIS-Wildlife Services, s_r100@yahoo.com

Daniel S. Vice

USDA/APHIS/WS

Darryl York

National Wildlife Research Center

Kenneth S. Gruver

National Wildlife Research Center

Follow this and additional works at: https://digitalcommons.unl.edu/icwdm_usdanwrc

Part of the Environmental Sciences Commons

Engeman, Richard M.; Vice, Daniel S.; York, Darryl; and Gruver, Kenneth S., "Sustained evaluation of the effectiveness of detector dogs for locating brown tree snakes in cargo outbound from Guam" (2002). USDA National Wildlife Research Center - Staff Publications. 483.

https://digitalcommons.unl.edu/icwdm_usdanwrc/483

This Article is brought to you for free and open access by the U.S. Department of Agriculture: Animal and Plant Health Inspection Service at DigitalCommons@University of Nebraska - Lincoln. It has been accepted for inclusion in USDA National Wildlife Research Center - Staff Publications by an authorized administrator of DigitalCommons@University of Nebraska - Lincoln. 


\title{
Sustained evaluation of the effectiveness of detector dogs for locating brown tree snakes in cargo outbound from Guam
}

\author{
Richard M. Engemanª ${ }^{\mathrm{a}}$, Daniel S. Vice ${ }^{\mathrm{b}}$, Darryl York ${ }^{\mathrm{a}}$ and Kenneth S. Gruver ${ }^{\mathrm{a}}$ \\ ${ }^{a}$ National Wildlife Research Center, 4101 Laporte Avenue, Fort Collins, CO 80521- \\ 2154, USA \\ ${ }^{\mathrm{b}}$ USDA/APHIS/WS, 1060 Route 16, Suite 103-C, Barrigada Heights, GU 96921, USA
}

Available online 7 November 2001.

\begin{abstract}
The accidental introduction of the brown tree snake Boiga irregularis to Guam has resulted in the extirpation of most of the island's native terrestrial vertebrates, has created a health hazard to infants and children, and has resulted in economic losses. The high brown tree snake population densities on Guam, the species' adaptations for successful dispersal, and Guam's position as a focal point for commercial and military cargo shipments have created a high level of concern that brown tree snakes could spread from Guam to colonize other vulnerable locations. Cargo inspections using teams of handlers and their detector dogs form the last line of defense for preventing brown tree snake dispersal from Guam. We assessed the efficacy of the teams of handlers and their dogs during 1998 and 1999 for locating stowed brown tree snakes by planting live brown tree snakes (in escape-proof containers) in cargo without the knowledge of the handlers inspecting the cargo. Many of these inspections were monitored by a concealed observer to determine the reason if a planted snake was not located by the dog teams. For 1998 and 1999 , we found similar efficacies of $61 \%$ and $64 \%$, respectively. When the snakes were not located by the dogs, we found that twice as many were missed because the dog did not change its behavior in response to the snake rather than because the handler did not conduct an adequate search pattern. During daytime inspections we found a greater efficacy for outdoor inspections than for indoor inspections. We found that the average efficacy of $62 \%$ for the 1998-99 period was lower than the baseline efficacy of $70 \%$ established in 1997.
\end{abstract}

Author Keywords: Boiga irregularis; Canine inspections; Exotic species

Published in International Biodeterioration \& Biodegradation

Volume 49, Issues 2-3 , 2002, Pages 101-106 


\title{
Sustained evaluation of the effectiveness of detector dogs for locating brown tree snakes in cargo outbound from Guam
}

\author{
Richard M. Engeman ${ }^{a, *}$, Daniel S. Vice ${ }^{\mathrm{b}}$, Darryl York ${ }^{\mathrm{a}}$, Kenneth S. Gruver ${ }^{\mathrm{a}}$ \\ "National Wildifie Research Conter. 4101 Laporte Avenue. Fort Collins. CO 80521-2154, USA

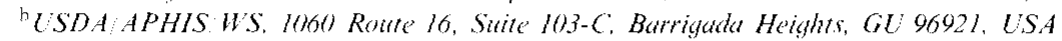

\begin{abstract}
The accidental introduction of the brown tree snake Boiga irregularis to Guam has resulted in the extirpation of most of the island's native terrestrial vertebrates, has created a health hazard to infants and children, and has resulted in economic losses. The high brown tree snake population densities on Guam, the species' adaptations for successful dispersal, and Guam's position as a focal point for commercial and military cargo shipments have created a high level of concern that brown tree snakes could spread from Guam to colonize other vulnerable locations. Cargo inspections using teams of handlers and their detector dogs form the last line of defense for preventing brown tree snake dispersal from Guam. We assessed the efficacy of the teams of handlers and their dogs during 1998 and 1999 for locating stowed brown tree snakes by planting live brown tree snakes (in escape-proof containers) in cargo without the knowledge of the handlers inspecting the cargo. Many of these inspections were monitored by a concealed observer to determine the reason if a planted snake was not located by the dog teams. For 1998 and 1999, we found similar efficacies of $61 \%$ and $64 \%$, respectively. When the snakes were not located by the dogs, we found that twice as many were missed because the dog did not change its behavior in response to the snake rather than because the handler did not conduct an adequate scarch pattern. During daytime inspections we found a greater efficacy for outdoor inspections than for indoor inspections. We found that the average efficacy of $62 \%$ for the $1998-99$ period was lower than the baseline efficacy of $70 \%$ established in 1997. (C) 2002 Elsevier Science Ltd. All rights reserved.
\end{abstract}

Keyrords: Boiga irregularis; Canine inspections; Exotic species

\section{Introduction}

The brown tree snake (Boiga irregularis) on Guam is a severe example of the negative effects that an introduced predator can have on native insular fauna (Savidge, 1987). This nocturnal snake, probably brought by accident to Guam in post World War II cargo shipments, has attained extraordinary population densities throughout the island (Rodda et al., 1992). As a result of snake predation, only 3 of 12 native species of forest birds survive in the wild, with one of them on the verge of elimination (National Research Council, 1997). The Guam population of Marianas fruit bat (Pteropus mariannus), already impacted by hunting, has been further decimated by snake predation (Wiles et al., 1995). Many of Guam's native species of lizards also have been negatively impacted by brown tree snake populations (Rodda and Fritts, 1992).

\footnotetext{
${ }^{*}$ Corresponding author. Tel.: +1-970-266-6091; fax: +1-970-2666089.

E-muil address: richard.m.engeman(ausda.gov (R.M. Engeman).
}

Guam also has suffered economic and social consequences of the brown tree snake introduction. Brown tree snakes prey on poultry and other small domesticated animals (Fritts and McCoid, 1991). They climb utility poles and wires, causing frequent power failures that result in millions of dollars of damaged equipment, lost productivity, and repair costs (Fritts et al., 1987). Furthermore, the brown tree snake is mildly venomous and readily enters buildings where it may present a health threat to small children (Fritts et al., 1990).

The brown tree snake may impact other islands in the future, as it is well-adapted for successful transport to other locations. They are agile climbers that seek refuge from heat and light during daytime, and cargo, shipping containers, and transport vessels may offer ready daytime refugia. The snakes are opportunistic feeders that consume a highly varied diet and can survive an extended period without food (Greene, 1989; Linnell et al., 1997; Rodda et al., 1999; Savidge, 1988; Shine, 1991; Shivik and Clark, 1999). Furthermore, mitochondrial DNA evidence suggests that very few, possibly only one, female brown tree snake originated 
the Guam population (Rawlings et al., 1998). These elements, coupled with the high snake densities and Guam 's position as a focal point for commercial and military shipments of cargo and passengers throughout the western $\mathrm{Pa}$ cific, magnify the likelihood for further dispersal of brown tree snakes from Guam. Brown tree snake sightings have been documented on many Pacific islands (Fritts et al., 1999), and an incipient population is speculated to exist on Saipan in the Commonwealth of the Northern Mariana Islands (McCoid et al., 1994).

As a response to the threat that brown tree snakes could invade other locations from Guam, a US Department of Agriculture/Wildlife Services (WS) program was established on Guam in late-1993 to deter the dispersal of brown tree snakes through cargo to vulnerable destinations (Engeman et al., 1998b; Vice et al., 1999). Low snake population buffer zones have been produced and maintained in the vicinities of air- and sea-ports, and other cargo staging areas by removing brown tree snakes during nighttime spotlight searches of fences (Engeman et al., 1999), and through trapping, which has been demonstrated to be a highly effective population reduction method in a number of studies (e.g., Engeman et al., 1998a, b; Engeman and Linnell, 1998). However, much of the cargo exported from Guam originates from areas of the island beyond where snake removal efforts are applied. Sometimes, following natural disasters, such as the typhoons which regularly strike Guam, other brown tree snake control technologies may be severely damaged, and detector dogs may be the only line of defense (Vice and Engeman, 2000). Inspections are not mandatory, but are made as a result of cooperative arrangements between the Wildlife Services program and the parties receiving inspections. An examination of the case histories for each snake located by detector dogs from 1993 through 1996 revealed that over $80 \%$ of those snakes were either in, or nearby, cargo with potential Pacific island destinations (Engeman et al., 1998c).

Events that increase cargo flow, such as large military exercises or responses to natural disasters, may increase the opportunity for snake dispersal. An increase in the brown tree snake discovery rate by dogs was found in the first 2 months following Supertyphoon Paka in December 1997, and $75 \%$ of those snakes also were in position to enter the cargo flow to Pacific Island destinations (Vice and Engeman, 2000). Extensive natural phenomena that alter the habitats on Guam may also promote brown tree snake entrance into cargo flows from Guam. Under these circumstances, the importance of detector dog team searches are maximized. For example, Supertyphoon Paka damaged many snake traps, destroyed structures and vegetation where traps were placed, and destroyed perimeter fences on which nightly spotlight searches were conducted. However, the dog teams were conducting inspections of outbound cargo the day following the typhoon (Vice and Engeman, 2000).

Monitoring and maintaining the efficacy of the detector dog program is vital to its success. The only previous study to examine efficacy evaluated different testing methods, and established a baseline efficacy of $70 \%$ (Engeman et al., 1998d). Since then, there have been numerous changes in handler personnel and older dogs have been retired and replaced with new dogs, and the island underwent and recovered from the tremendous devastation by Supertyphoon Paka. In addition to basic quality assurance needs for monitoring efficacy of the dog teams, these changing circumstances have placed a premium on determining whether efficacy has been affected. We report the results from monitoring the efficacy of dog teams for the two years subsequent to development of baseline information, 1997-1999.

\section{Methods}

\subsection{Standard inspection procedures}

Cargo, cargo staging areas, and transport vessels identified as posing a risk (Vice et al., 1999) for accidental introduction of a brown tree snake to a vulnerable location are subjected to inspections by detector-dog teams. A detector-dog team comprises a handler and the unique detector-dog (Jack Russell Terriers) assigned to that handler. A varicty of commercial and military facilities are inspected (Engeman et al., 1998c; Vice and Engeman, 2000), and each handler is responsible for organizing the inspections at his/her assigned inspection sites within his/her assigned time frame. Close coordination with managers of facilities is required to insure that outbound cargo, and transport vessels when necessary, are inspected. Inspection of some large cargo facilities may require two or three dog teams.

\subsection{Placement of test snakes}

We planted live brown tree snakes in cargo in advance of inspections and without the knowledge of the handler(s) responsible for conducting the inspection. Prior to placement in cargo, we put the snakes in escape-proof containers, either capped and ventilated PVC pipes $\left(28 \times 4 \mathrm{~cm}^{2}\right.$ diameter), or small hardware cloth cages capped on each end $\left(21 \times 6 \times 6 \mathrm{~cm}^{3}\right)$. Ventilation in the containers allowed the snake scent to escape and the snakes to breathe. Because free-ranging, wild snakes had been discovered in a wide variety of cargo situations (Engeman et al., 1998c), we randomly hid our snakes at various depths within the cargo, or in the immediate vicinity of the cargo, making sure that the snake containers were not visible to the handlers or dogs. Facility employees cooperated well with our request to not intentionally or unintentionally alert the handlers when a snake had been planted. To insure that dogs did not key on odors left on containers by previous snakes or mouthing by dogs, we thoroughly washed containers with soap and water prior to reusing them and we also conducted numerous 
trials to verify that the dogs could not detect empty cleaned containers that had been hidden.

Dog handlers were always under instructions to report any snakes located in cargo, wild or planted. All snakes that were not located by the dogs and their handlers were retrieved, and facility employees at the inspection sites were shown the locations of planted snakes and instructed to remove them if the cargo had to be moved. As an additional precaution for the accidental shipment of planted snakes, the containers were labeled as Federal property containing live brown tree snakes, not to open, and contained a phone number for instructions.

\subsection{Concealed observers}

The above protocol provided an unbiased assessment of efficacy for locating snakes, but could not provide information on why snakes might escape detection during an inspection. To do so, we placed an observer out of sight of the handlers at inspection sites for as many of the trials with planted snakes as possible. These observations were conducted discreetly from inside a parked car, from a distance using binoculars, or concealed in an office or room of the inspected facility in a location where the observer could not be seen by the handler. For these trials we collected data on the dog team's success for locating each planted snake, as well as observations on the search procedures. Important information included whether the handler placed the dog in a position where it was likely to detect a planted snake, and whether the dog gave a discernable behavior change when it was in a good position to detect the snake. Out of logistical constraints, large amounts of these data were difficult to obtain. Prior to the arrival of the handlers with their dogs at an inspection site, the observer had to plant snakes and position himself such that he could make observations without being seen. While we found it surprisingly easy to conceal observers where they could monitor the handler's and dog's actions without alerting them to their presence, this had to be accomplished without precise knowledge of the inspection schedule, other than knowledge that an inspection of the facility would take place during that shift. Otherwise, handlers might have been alerted to the potential for a snake to be planted at one of his/her inspection sites.

\subsection{Data collection and analyses}

We collected data between October 1997 and September 1999. We refer to these years as 1998 (10/97-9/98) and 1999 (10/98-9/99). For each snake planted we recorded the date, the site, the cargo type in (or next to) which the snake was planted, whether it was indoors or outdoors, whether it was raining, the identity of the person planting the snake, and whether the snake was discovered. We obtained information on the time of inspection, the number of dog teams used and their identities (both handlers and dogs) from a log book filled out by the handlers for each inspection at each facility. These latter data also could be recorded directly when a concealed observer was used. In addition, if a snake was not discovered, the concealed observer recorded the reasons why and any related circumstances.

The data collected were categorical. Where cell sizes were adequate, Pearson's $\chi^{2}$ test was used to examine differences in proportions. For situations with small cell sizes, Fisher's "exact" test was used.

\section{Results}

In 1998, 77 brown tree snakes were planted and inspected by dog-teams. Of these, 34 were monitored by a concealed observer. In 1999 only 36 brown tree snakes were planted, but 35 were monitored by concealed observer (Table 1 ). The discovery rate of $61 \%$ (47 of 77 ) for 1998 was similar to the $64 \%$ (23 of 36) rate for $1999\left(\chi^{2}=0.085, \mathrm{df}=1, p=0.77\right)$, and indicated some consistency between the years. Of the 16 planted snakes that were missed during the inspections monitored by a concealed observer in 1998, 10 were missed due to a lack of a behavior change by the dog that would indicate the presence of a snake, 5 were missed due to the handler conducting an inadequate search pattern that gave the dog an insufficient opportunity to locate the snake, and 1 was not determined. The same 2:1 ratio of dog-to-handler sources for missed snakes was repeated in 1999. Of the 13 snakes missed in the presence of a concealed observer, 8 were due to lack of a behavior change by the dog, 4 were missed due to inadequate search patterns, and 1 was not determined.

We used the 113 total planted snake observations from 2 years to examine some of the environmental factors that might influence efficacy for discovering brown tree snakes during dog-team inspections. Guam's hot, humid climate could affect energy levels and attentiveness of handlers and dogs alike. Therefore, we compared efficacy between nighttime and daytime inspections, and between indoor and outdoor inspections during daytime. Insufficient numbers of inspections prevented comparison of indoor and outdoor inspections for nighttime. Similarly, insufficient numbers of observations were available to examine the effect of rain on outdoor searches.

The large majority ( $88 \%$ ) of observations occurred during daytime. Although the efficacy for discovering snakes during daytime $(58 \%)$ was lower than for nighttime $(69 \%)$, the difference was not statistically detectable $\left(\chi^{2}=0.565\right.$, df $=$ $1, p=0.45)$. The efficacy for daytime outdoor inspections $(70 \%)$ exceeded that for indoor inspections $(49 \%)\left(x^{2}=\right.$ 4.242, df $=1, p=0.039$ ).

The overall efficacy of $62 \%$ for $1998-99$ showed a decrease from the baseline (Engeman et al., 1998d) of $70 \%$ ( $\chi^{2}=4.482$, df $=1, p=0.034$ ). The proportion of snakes missed due to nonresponse by the dogs versus inadequate search patterns by the handlers appeared to shift from the 
Table 1

Summary of detector dog team inspection results for discovering brown tree snakes planted to test efficacy from October 1997 through September $1999^{\text {a }}$

\begin{tabular}{|c|c|c|c|c|c|c|c|}
\hline \multirow[b]{2}{*}{ Year } & \multicolumn{2}{|c|}{ No. of Snakes } & \multirow[t]{2}{*}{ Discovery rate $(\%)$} & \multirow[t]{2}{*}{ No. monitored by concealed oberver } & \multicolumn{3}{|c|}{ Misses observed by concealed oberver } \\
\hline & Planted & Found & & & Dog & Handler & Other \\
\hline 1998 & 77 & 47 & 61 & 34 & 10 & 5 & 1 \\
\hline 1999 & 36 & 23 & 64 & 35 & 8 & 4 & 1 \\
\hline Total & 113 & 70 & 62 & 79 & 18 & 9 & 2 \\
\hline Baselinea & 50 & 35 & 70 & 19 & 3 & 4 & 0 \\
\hline
\end{tabular}

Bascline results from 1997 are also presented. Taken from Engeman et al. (1998d).

baseline of $43-67 \%$ here, but this change was not statistically detectable for the small sample of observed misses (Fisher's "exact" test, $p=0.387$ ). If we combine the present data with the previous baseline, we define a new baseline efficacy of $64 \%$ for future comparisons of efficacy.

\section{Discussion}

Despite the decline in efficacy by $11 \%$ over the 2 years, the present discovery rate of $62 \%$ of brown tree snakes in cargo can be considered a significant achievement. During the 1998-99 time frame, the detector dog program experienced a high turnover in handlers while some of the more experienced dogs had to be retired due to old age and replaced with younger dogs. New dogs and new handlers could be expected to reduce probabilities for finding planted snakes, even given that substantial training requirements must be passed before new dogs are allowed to inspect independently. Efficacy showed a small, but not statistically detectable increase from 1998 to 1999 . Continued monitoring would be needed to evaluate whether this is an indication of a trend for improved efficacy.

We did not expect that the efficacy for daytime outdoor inspections would exceed that for indoor inspections. We expected that working directly in the daytime heat would diminish the energy and attentiveness of handlers and dogs alike, resulting in lower efficacy. However, except for during the actual inspection, the dogs are kept in air conditioned vehicles. There probably is sufficient rest time in a climate-controlled environment that the outdoor inspections are not much more taxing than indoor inspections. The reasons for lower detectability indoors may have been that indoor inspections, while shaded, are in an environment with more stagnant air that can hold a variety of odor plumes, such as from forklift exhaust, from chemicals used at the facilities, or from the chemical signatures of the variety of cargoes stored in the facility. These competing non-target odor plumes may distract from, overwhelm, or otherwise mask the scents from brown tree snakes, and thereby decrease the probability of detection.

We were not able to find a statistical distinction between the slightly higher detection rate of $69 \%$ during nighttime searches versus the $58 \%$ rate for daytime searches. While a larger data set might provide more insight as to whether a time of day effect exists, we should note that most discoveries of naturally occurring snakes in cargo have occurred at night (US Department of Agriculture/Wildlife Services, unpublished data). Undoubtedly this is largely because brown tree snakes are active at night, but it also could be influenced by an increased likelihood for detecting target odors during nighttime conditions.

We attempted to distinguish sources of error for misses of planted snakes by identifying occasions where the handler did not apply a sufficient search pattern, or the dog did not show a noticeable change in behavior to indicate that a snake had been detected. Changes in dog behavior in response to a snake can vary among dogs and can be subtle. Handlers, especially in new dog teams, may have difficulty discerning or correctly interpreting subtle cues. A concealed observer at a distance would be expected to have greater difficulty, although that observer would have the advantage of knowing where the snakes were planted, and thus be able to anticipate even subtle behavior changes. Thus, it is possible that what we have labeled as canine error may actually be a combined error where the dog fails to provide a sufficient behavioral cue to the handler, and/or the handler fails to accurately read the behavior.

We have examined the efficacy of dog teams for discovering brown tree snakes in cargo outbound from Guam, but two programs use dogs to inspect for brown tree snakes inbound from Guam. A small program ( 3 dog teams) is in place on Oahu, Hawaii where beagles are used to inspect inbound cargo for brown tree snakes (Imamura, 1999), and are cross-trained for agricultural inspections (Kaichi, 1998). A program with 2 dog teams using Jack Russell terriers operates in Saipan of the CNMI, also primarily to inspect inbound cargo for brown tree snakes (Vogt, 1998). Both the Hawaii and Saipan dog programs are hampered by limited opportunities for testing and training with live brown tree snakes, making it unlikely their detection efficacy is as high as reported for the dogs on Guam. Because these islands are considered at high risk for invasion by brown tree snakes, there are some inherent risks in applying our approach of testing efficacy with live brown tree snakes on those islands, even when using escape-proof containers. These risks for testing efficacy place a greater premium on detector dog inspections of outbound cargo on Guam, 
along with a concurrent understanding of the efficacy of the method.

A number of other objectives can be addressed if the results of a sufficient number of trials are maintained in a database for comparative purposes. With enough detail in observations, the effect on efficacy from specific situations might be better understood such that management might efficiently respond to situations where efficacy might be diminished. Examples besides comparing indoor versus outdoor inspection efficacies include sensitive evaluations of the effect on efficacy from daytime versus nighttime inspections, rain, temperature, or different types of cargo. Similarly, management would be able to evaluate when a new dog or handler had achicved sufficient proficiency to independently conduct inspections. As new training procedures are implemented and those dogs included in the operational program, the efficacy resulting from the new procedures could be evaluated in practice. A long-term database would permit monitoring of the program as new training procedures are incorporated, and it would permit examination of the lag time between implementation of new training procedures and results in practice.

We have to consider how well the detection rate for planted snakes compares to the detection rate for snakes occurring naturally in cargo. It is possible, but unknown whether naturally occurring snakes select refugia in cargo with less air (and chemical) exchange than occurs with snakes held in containers. While we can only speculate on this point, we can be sure that snakes planted in containers cannot leave a scent trail, whereas a snake that has crawled into cargo may leave a trail that would facilitate detection. Also, naturally occurring snakes most likely (but not always) would have entered cargo prior to arrangement for export where inspections occur. Thus, more time would probably elapse for an odor plume to accumulate than for planted snakes in containers. Based on these final points, we feel that planted snakes may well offer a conservative (more severe) test of the dogs' abilities to detect naturally occurring snakes.

Perhaps the most important benefit to accrue from continued monitoring of dog team efficacy is that regular, undisclosed plants of brown tree snakes at inspection sites helps to improve and maintain efficacy (Engeman et al., 1998d). In addition, concealed observers can provide information on why snakes might be missed, and where management can focus training. Until new methods for reducing brown tree snake populations island-wide are discovered, funded, and implemented, detector dog inspections will be a key component for preventing brown tree snake dispersal to other locations.

\section{Acknowledgements}

R. Bruggers, K. Fagerstone, M. Fall, T. Mathies, P. Savarie and J. Shivik provided valuable reviews of the paper. This research was conducted under funding provided to the US Department of Agriculture/Animal and Plant Health Inspection Service/Wildlife Services/Washington State Director's Office by the US Department of Defense under DOD MIPR-064-95, "Operational Control of Brown Tree Snakes in Guam".

\section{References}

Engeman, R.M., Linnell, M.A., 1998. Trapping strategies for deterring the spread of brown tree snakes (Boiga irregularis) from Guam. Pacific Conservation Biology 4, 348--353.

Engeman, R.M., Linnell, M.A.. Pochop, P.A., Gamboa, J., 1998 a. Substantial reductions of brown tree snake (Boiga irregularis) populations in blocks of land on Guam through operational trapping. International Biodegradation \& Biodeterioration 46. 167171.

Engeman, R.M., Linnell, M.A., Vice, D.S., Pitzler, M.E.. 1998b. Efficacy of the methods used in an integrated program to deter the spread of brown tree snakes from Guam. Proceedings Australian Vertebrate Pest Conference 11, 435-440.

Engeman, R.M., Rodriguez, D.V., Linnell, M.A.. Pitzler, M.E.. 1998c. A review of the case histories of brown tree snakes (Boiga ireqularis) located by detector dogs on Guam. International Biodegradation \& Biodeterioration 42, 161-165.

Engeman, R.M., Vice, D.S., Rodriguez, D.V., Gruver, K.S., Santos, W.S., Pitzler, M.E., 1998d. Effectiveness of detector dogs for locating brown tree snakes in cargo. Pacific Conservation Biology 4, 348-353.

Engeman, R.M., Linnell, M.A., Aguon, P.. Manibusan, A., Sayama, S.. Techaira, A., 1999. Implications of brown tree snake captures from fences. Wildlife Research 26, 111116.

Fritts, T.H., McCoid, M.J., 1991. Predation by the brown tree snake (Boigla irregularis) on poultry and other domesticated animals on Guam. The Snake 23, 75-80.

Fritts, T.H., Scott, N.J., Savidge, J.A., 1987. Activity of the arboreal brown tree snake (Boiga irregularis) on (juam as determined by electrical outages. The Snake 19, 51-58.

Fritts, T.H., McCoid, M.J., Haddock, R.L., 1990. Risks to infants on Guam from bites of the brown tree snake (Boing irregularis). American Journal of Tropical Medicine and Hygiene 42, 607-611.

Fritts, T.H., McCoid, M.J., Gomez, D.M., 1999. Dispersal of snakes to extralimital islands: incidents of the brown tree snake (Boigu irreyularis) dispersing to islands in ships and aircraft. In: Rodda, G., Sawai, Y., Chiszar, D., Tanaka, H. (Eds.), Problem Snake Management: The Habu and Brown Tree snake. Cornell Univ Press, Ithaca, NY, pp. 209-223.

Greene, H.W., 1989. Ecological, evolutionary, and conservation implications of feeding biology in Old World cat snakes, genus Boicha (Colubridae). Proceedings of the California Academy of Sciences 46, 193-207.

Imamura, C.K., 1999. A preliminary examination of public policy issues in the use of canine detection of brown treesnakes. In: Rodda. G., Sawai, Y., Chiszar, D., Tanaka, H. (Eds.), Problem Snake Management: The Habu and Brown Tree snake. Cornell Univ Press, Ithaca, NY, pp. $353-362$.

Kaichi, L., 1998. An overview of the state of Hawail's detector dog program. Brown Tree snake Rescarch Symposium. Honolulu, HI, 23 pp.

Linnell, M.A., Rodriguez, D.V., Mauldin, R.E., Engeman, R.M., 1997. Boiga irregularis: incubation and diet. Herpetological Review 28.153.

McCoid, M.J., Fritts, T.H., Campbell III, E.W., 1994. A brown tree snake (Colubridae: Boiga irregularis) sighting in Texas. Texas Journal of Science 46, 365 368 .

National Research Council, 1997. The Scientific Bases for the Preservation of the Mariana Crow. National Academy Press, Washington. DC.

Rawlings, L.R., Whittier, J., Mason, R.T., Donncllan, S.C.. 1998. Phylogenctic analysis of the brown treesnake, Boigu irregularis, 
particularly relating to a population on Guam. Brown Tree snake Research Symposium. Honolulu, HI, $31 \mathrm{pp}$.

Rodda, G.H., Fritts, T.H., 1992. The impact of the introduction of the colubrid snake Boiga irregularis on Guam's lizards. Journal of Herpetology 26, 166-174.

Rodda, G.H., Fritts, T.H., Conry, P.J., 1992. Origin and population growth of the brown tree snake, Boiga irregularis, on Guam. Pacific Science 46, 46-57.

Rodda, G.H., Fritts, T.H., McCoid, M.J., Campbell III, E.W., 1999. An overview of the biology of the brown treesnake in small plots. In: Rodda, G., Sawai, Y., Chiszar, D., Tanaka, H. (Eds.), Problem Snake Management: The Habu and Brown Tree snake. Cornell Univ Press, Ithaca, NY, pp. 44-80.

Savidge, J.A., 1987. Extinction of an island forest avifauna by an introduced snake. Ecology 68, 660 668 .

Savidge, J.A., 1988. Food habits of Boiga irregularis, an introduced predator on Guam. Journal of Herpetology 22, 275-282.
Shine, R., 1991. Strangers in a strange land: ecology of Australian colubrid snakes. Copeia 1991, 120-131.

Shivik, J.A., Clark, L., 1999. Ontogenetic shifts in carrion attractiveness to brown tree snakes (Boiga irregularis). Journal of Herpetology 33 , 334-336.

Vice, D.S., Engeman, R.M., 2000. Brown tree snake discoveries during detector dog inspections following Supertyphoon Paka. Micronesica 33, $105-110$.

Vice, D.S., Linnell, M.A., Pitzler, M.E. 1999. Summary of Guam's outbound cargo process: preventing the spread of the brown tree snake. Working Draft Report, USDA/APHIS/Wildlife Services, Guam District.

Vogt, S.R., 1998. Detector dogs on Saipan. Brown Tree snake Research Symposium. Honolulu, HI, 23pp.

Wiles, G.J., Aguon, C.F., Davis, G.W., Grout, D.J., 1995. The status and distribution of endangered animals and plants in northern Guam. Micronesica 28, 31-49. 